\title{
Influenza: La importancia de la vigilancia y prevención
}

\author{
Influenza: Importance of vigilance and prevention
}

La Influenza es una enfermedad viral respiratoria que causa morbimortalidad importante por poder presentarse no solo de manera estacional sino también en epidemias cuando surge una nueva cepa ante la cual no ha habido inmunidad previa. Se van a ver afectados especialmente en grupos de alto riesgo como son los muy pequeños o los ancianos o personas con enfermedades crónicas (1). Se estima que cada año la influenza afecta entre 5 a $15 \%$ de la población mundial y causa anualmente entre 250000 y 500000 muertes al año. Las epidemias de Influenza ocurren usualmente durante el otoño y el invierno en países de clima templado. En países como el nuestro se ha observado sin embargo un patrón distinto, en las zonas cálidas de la costa y en la selva donde hay una gran humedad y altas temperaturas, la transmisión del virus de Influenza ocurre a lo largo de todo el año, mientras en las zonas secas de los andes es en la época de invierno donde se dan con mayor frecuencia los casos de Influenza (2).

En Estados Unidos se estima que las muertes asociadas a la Influenza varían entre 3000 y 48000 durante un brote estacional. La temporada de influenza 2011-2012 fue una de las más leves de las últimas décadas, a pesar que predominaron los virus Influenza A(H3N2), los cuales usualmente se han asociado a mayores tasas de complicaciones y muerte que los virus de Influenza A estacional (H1N1) y que la Influenza B (3). El año pasado se describieron también cepas de Influenza A (H3N2) de origen porcino, que no están incluidas en las vacunas. Este año se ha visto un incremento en el número de casos de Influenza durante los primeras semanas de invierno en los Estados Unidos, mayor que lo visto desde la temporada 2003-2004, observándose una mayor frecuencia de casos asociada al virus de Influenza estacional subtipo H3N2. Esto originó en su momento gran preocupación en la comunidad médica y en la población. Sin embargo, en la última actualización del Centro de Control de Enfermedades de los Estados Unidos (CDC) se reporta que si bien de todos los casos de Influenza tipificados, el 93\% de los casos de Influenza A han sido casos de H3N2, la cepa está incluida en la vacuna para la actual temporada de gripe, hecho que probablemente ha influido en que el impacto de la enfermedad no haya sido lo que se temía (4).

En Perú se han realizado estudios a cargo de la Dirección de Epidemiología del Ministerio de Salud en equipo con la Unidad de investigación Médica de la Marina Americana (NAMRU-6) (2,5). Antes de la pandemia del 2009, ambas instituciones ya venían realizando un estudio de vigilancia de enfermedad tipo influenza realizado entre junio de 2006 y mayo de 2008. Se definió enfermedad tipo Influenza como la presencia de fiebre mayor de $38^{\circ} \mathrm{C}$ y tos o dolor faríngeo de menos de 5 días de duración. El estudio se realizó en 13 ciudades de Perú de las zonas geográficas más representativas del país. Se encontró al menos un agente viral respiratorio en $42,6 \%$ de los 6835 pacientes reclutados. Se encontró con mayor frecuencia Influenza A (25,1\%), Influenza B (9,7\%), virus Parainfluenza 1, 2 y 3 $(3,2 \%)$, virus herpes simple $(2,6 \%)$ y adenovirus $(1,8 \%)(2)$. El análisis genético de los virus Influenza encontró que había 3 cepas de Influenza A H1N1, una de Influenza A H3N2, y dos de Influenza B durante el periodo de estudio. Este análisis genético mostro que las cepas H1N1 que circularon en el Perú no estaban incluidas en la vacuna recomendada para ese año. Todo lo contrario con las cepas de Influenza A H3N2 que circularon en el Perú durante los años 2007 y 2008, siendo similares a la que contenía la vacuna del 2008 para el hemisferio Sur. En cuanto a la Influenza B, de las dos cepas halladas solo una estaba incluida en la vacuna del hemisferio Sur. Estos datos muestran la importancia de realizar estudios de vigilancia continua. Otro hallazgo importante del estudio fue que $15 \%$ de los participantes habían recibido antibióticos en forma innecesaria antes de ser enrolados en el estudio. Las pruebas rápidas de Influenza permitirían un diagnóstico temprano de enfermedad viral y así evitar el uso innecesario de antibióticos. 
Durante el año de la pandemia del 2009 por la Influenza H1N1 se había reforzado aún más la vigilancia a cargo del Ministerio de Salud y el NAMRU, con el fin de detectar casos en forma temprana e implementar medidas preventivas. Para esto se venía realizando un estudio de cohorte poblacional domiciliario para el estudio de enfermedad tipo Influenza. Se escogió al azar más de 2500 familias, incluyendo más de 10000 personas, en 5 regiones geográficas representando nichos ecológicos diversos. Se visitan estas familias 3 veces por semana y se toman muestras nasofaríngeas de los sujetos que cumplían con la definición de caso de Enfermedad tipo Influenza. Luego se realizan pruebas rápidas y estudios moleculares para determinar las características de los virus de Influenza identificados (5). Una de las ventajas de este estudio es también el realizar consejería a las familias, haciendo énfasis en áreas como la nutrición, vacunas y uso adecuado de antibióticos. Durante la epidemia de Influenza A H1N1 se demostró claramente como la cepa pandémica reemplazó a la cepa A (H1N1) estacional. Este mismo estudio ha mostrado como hasta el 2011, solo $32 \%$ de los casos de enfermedad tipo Influenza han sido causados por el virus Influenza, encontrándose otros agentes virales como son coronavirus, metapneumovirus humanos, bocavirus humanos, rinovirus, enterovirus y virus parainfluenza.

La vigilancia para Influenza se ha realizado en pocos países en vías de desarrollo, incluyendo Bangladesh, Guatemala, India, Kenya y Nicaragua. Esto es esencial no solo para entender mejor la epidemiologia de la Influenza en países como el nuestro, sino para evaluar las cepas activas y ver la eficiencia de las vacunas. Esto último es importante puesto que los virus circulantes pueden cambiar en antigenicidad así como en susceptibilidad a los antivirales. Un estudio reciente ha mostrado que la eficacia de la vacuna inactivada en adultos jóvenes y de edad mediana es de $62 \%$ (rango entre 16 y $76 \%$ ) (6). Este año en Estados Unidos las cepas de la vacuna son antigénicamente similares a las que circulan en la comunidad en el $90 \%$ de cepas. Se estima que la eficacia de la vacuna contra la Influenza en los Estados Unidos para la temporada actual es de 62\% (7).

En la actual temporada de influenza en Estados Unidos predominan las cepas de Influenza A y B susceptibles a los inhibidores de la Neuraminidasa. Un meta análisis realizado a partir de 90 estudios observacionales, la mayoría durante la pandemia del 2009, encontró que el tratamiento antiviral iniciado dentro de las primeras 48 horas del inicio de síntomas redujo el riesgo de admisión a cuidados intensivos y el riesgo de muerte (8). Otros estudios con oseltamivir han mostrado incluso que hay cierto beneficio aun iniciando el tratamiento hasta 5 días después del inicio de síntomas (9). En los pacientes con sospecha de resistencia a oseltamivir, el zanamivir endovenoso sería un alternativa habiendo aun limitada experiencia en casos severos (10).

Para los profesionales de la salud es importante recordar como el virus Influenza puede representar un serio problema de salud, especialmente de aparecer cepas epidémicas. La prevención es importante y en Estados Unidos el Centro de Control de Enfermedades (CDC) ahora recomienda la vacuna para todas las personas mayores de 6 meses de edad en adelante, con énfasis en poblaciones de alto riesgo como son niños entre 6 meses y 4 años, adultos mayores de 50 años, pacientes con enfermedades crónicas pulmonares, cardiovasculares (excepto hipertensión), enfermedad hepática, renal, neurológica o enfermedades metabólicas (incluyendo diabetes), inmunosuprimidos, mujeres en edad fértil que podrían quedar embarazadas durante la temporada de Influenza, personal de salud y contactos de las pacientes de alto riesgo (11). En nuestro país aún no existe una clara conciencia de la necesidad de vacunación contra la Influenza, creemos que en grupos de alto riesgo la vacuna debe indicarse.

Felicitamos los esfuerzos de la Dirección de Epidemiología del Ministerio de Salud y del NAMRU-6 en equipo con el Centro de Control de Enfermedades de los Estados Unidos y la academia en realizar estudios de vigilancia de Influenza en nuestro país. Estamos seguros que los resultados serán de beneficio para toda nuestra comunidad, para no solo entender mejor la epidemiologia de las infecciones respiratorias virales agudas, sino para detectar rápidamente diferentes estadios de enfermedad en caso de que se produzca una nueva pandemia.

Luis Manuel Valdez ${ }^{1}$ 


\section{REFERENCIAS BIBLIOGRÁFICAS}

1. World Health Organization. Influenza (Seasonal). Fact Sheet $\mathrm{N}^{\circ}$ 211(Internet). Geneva: World Health Organization; 2009. (Citado el 6 de febrero 2013). Disponible en: http://www.who.int/mediacentre/fact sheets/fs211/en/index.html

2. Laguna-Torres VA, Gomez J, Ocana V, Aguilar P, Saldarriaga $T$. et al. Influenza like Illness Sentinel Surveillance in Peru. PLos One 2009; 4:e6118.

3. Bresee J, Hayden FG. Epidemic influenza. Respond ing to the expected but unpredictable. N Eng J Med. (Internet) 2013; 368:589-592. (Citado el 6 de febrero del 2013). Disponible en: http://www.nejm.org/doi/ full/10.1056/NEJMp1300375

4. Centers for Disease Control and Prevention, National Center for Immunization and Respiratory Diseases (NCIRD). Situation Update: Summary of Weekly FluView (Internet). (Citado el 10 de febrero del 2013). Disponible en: http://www.cdc.gov/flu/ weekly/summary.htm .

5. Razuri H, Romero C, Tinoco Y, Guezala MC, Ortiz E. et al. Population Based Active surveillance cohort studies for influenza: Lessons from Peru. Bull World Health Org. 2012; 90:318-320.

6. Osterholm MT, Kelley NS, Sommer A, Belongia EA. Efficacy and effectiveness of influenza vaccines: a systematic review and meta-analysis. Lancet Infect Dis. 2012; 12:36-44. [Erratum, Lancet Infect Dis 2012; 12:655.]

7. Centers for Disease Control and Prevention. Early estimates of seasonal influenza vaccine effectiveness - United States, January 2013. MMWR. 2013; 62 (2):32-35.

8. Muthuri SG, Myles PR, Venkatesan S, Leonardi-Bee J, Nguyen-Van-Tam JS. Impact of neuraminidase inhibitor treatment on outcomes of public health importance during the 2009-10 influenza A (H1N1) pandemic: a systematic review and meta-analysis in hospitalized patients. J Infect Dis. 2013; 207(4): 553563.

9. Louie JK, Yang S, Acosta M, et al. Treatment with neuraminidase inhibitors for critically ill patients with influenza A (H1N1) pdm09. Clin Infect Dis. 2012; 55:1198-1204.

10. Harter G, Zimmermann O, Schubert A, Mertens T, Kern P, Wohrle J. Intravenous zanamivir for patients with pneumonitis due to pandemic (H1N1) 2009 Influenza virus. Clin Infect Dis 2010; 50:1249-51.

11. Centers for Disease Control and Prevention, National Center for Immunization and Respiratory Diseases (NCIRD). Influenza Vaccination. A summary for Clinicians (Internet). (Citado el $10 \mathrm{de}$ febrero del 2013). Disponible en: http://www.cdc. gov/flu/professionals/vaccination/vax-summary.htm

1 Editor Asociado Revista Médica Herediana. Lima, Perú. 